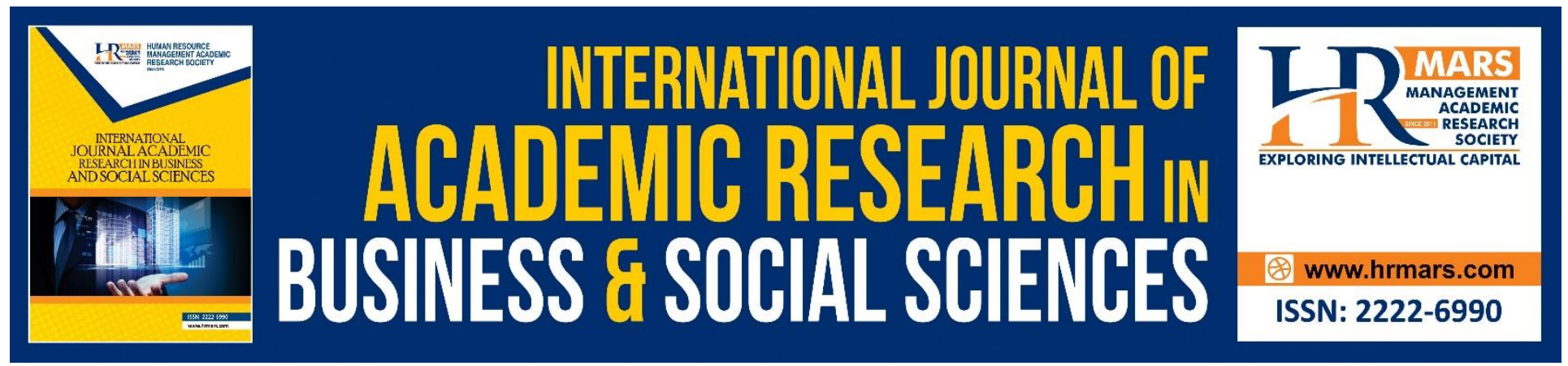

\title{
Malay Gamelan and String Ensemble Cultural Hybridity: Instructional Material Development for Teaching Intermediate University-level String Ensemble Class Using Gamelan Repertories
}

\section{Shafizan Sabri, Mahayuddin Abdul Rahim, Colleen Wong Huey Yi}

To Link this Article: http://dx.doi.org/10.6007/IJARBSS/v9-i2/5551

DOI: $\quad 10.6007 /$ IJARBSS/v9-i2/5551

Received: 29 Jan 2019, Revised: 24 Feb 2019, Accepted: 11 March 2019

Published Online: 19 March 2019

In-Text Citation: (Sabri, Rahim, \& Yi, 2019)

To Cite this Article: Sabri, S., Rahim, M. A., \& Yi, C. W. H. (2019). Malay Gamelan and String Ensemble Cultural Hybridity: Instructional Material Development for Teaching Intermediate University-level String Ensemble Class Using Gamelan Repertories. International Journal of Academic Research in Business and Socal Sciences, 9(2), 364-383.

Copyright: (C) 2019 The Author(s)

Published by Human Resource Management Academic Research Society (www.hrmars.com)

This article is published under the Creative Commons Attribution (CC BY 4.0) license. Anyone may reproduce, distribute, translate and create derivative works of this article (for both commercial and non-commercial purposes), subject to full attribution to the original publication and authors. The full terms of this license may be seen at: http://creativecommons.org/licences/by/4.0/legalcode

Vol. 9, No. 2, 2019, Pg. 364 - 383

Full Terms \& Conditions of access and use can be found at http://hrmars.com/index.php/pages/detail/publication-ethics 


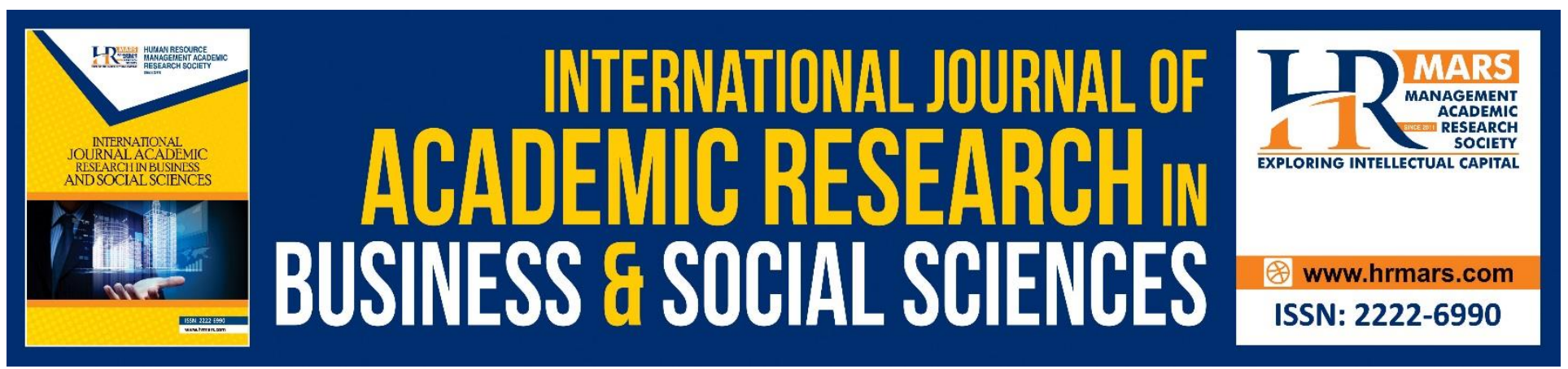

\title{
Malay Gamelan and String Ensemble Cultural Hybridity: Instructional Material Development for Teaching Intermediate University-level String Ensemble Class Using Gamelan Repertories
}

\author{
Shafizan Sabri
}

Faculty of Music and Performing Arts, Sultan Idris Education University, Perak, Malaysia

Mahayuddin Abdul Rahim

Faculty of Music and Performing Arts, Sultan Idris Education University, Perak, Malaysia

\section{Colleen Wong Huey Yi}

Faculty of Music and Performing Arts, Sultan Idris Education University, Perak, Malaysia

\begin{abstract}
While humbly accepting scholarly opinions that hybridity is a global trend in cultural research, theory and criticism, and one of the most broadly utilized and reprimanded ideas in postcolonial theory, this research is a response to the already extant that western and non-western fusion is practicable. During cultural hybridization process, traditional components will not die out however will develop into a spectacular form. Tradition isn't something made stale or worn after some time, nonetheless develops throughout the years. From this perspective, the researcher decided to design a hybrid project that would cross cultural boundaries and bring the researcher into music and interpersonal dialogue between western and non-western elements. Two distinct elements which are the traditional Malay gamelan repertories and string ensemble as the Western instruments were brought together to create a work of intercultural beauty, respectful to both musical traditions and to the artists who practice them. The study attempts to create new arrangement for string ensemble using selected traditional Malay gamelan repertories and use these pieces as instructional material for teaching intermediate university-level string ensemble class. The results of the study assists music educator in developing instructional material which hybridized other Malaysian traditional music with western instruments.
\end{abstract}


INTERNATIONAL JOURNAL OF ACADEMIC RESEARCH IN BUSINESS AND SOCIAL SCIENCES

Vol. 9, No. 2, Feb, 2019, E-ISSN: 2222-6990 C 2019 HRMARS

Keywords: Malay Gamelan, String Ensemble, Cultural Hybridity

\section{INTRODUCTION}

The evolution of technologies and social media have exposed composers, performers, listeners, and researches in the twenty-first century to vast amounts of musical styles and traditions from around the world. In regard to this revolution, Wappel (2016) emphasizes that:

Technological advances in cross-cultural communications have characterized the latter decades of the twenty-first century and are a major factor in the intercultural encounters that have given rise to fusions of Western and Eastern music. Increased international exposure through print, radio, television, and the Internet has softened the lines of division between disparate societies. Day by day, as nations converge and largely isolated cultures open their doors to new ideas and concepts, it is becoming more and more important to seek cultural awareness and understanding (p.1).

Academic interest in cross-cultural endeavours has risen considerably in recent years. This can be seen by the number of papers published to celebrate these new phenomena. As highlighted by Burke (2009): A recent discussion of post-modernity-by the British historian Perry Anderson, describes the tendency of the period we live in to celebrate the 'cross-over, the hybrid, the pot-pouri' (p.1). Burke (2009) also put bring to light that:

However, we react to it, this global trend is impossible to miss, from curry and chips - recently voted the favourite dish in Britain - to Thai saunas, Zen-Catholicism or Judaism, Nigerian Kung Fu, or 'Bollywood' films, made in Bombay-Mumbai and mixing Indian traditions of song and dance with the conventions of Hollywood. This process is particularly obvious in the domain of music, in the case of such hybrid forms and genres as jazz, reggae, salsa, or more recently, flamenco rock and Afro-Cedric rock. New technology - including, appropriately enough, the 'mixer' - has obviously facilitated this kind of hybridization (p.2-3).

While humbly accepting scholarly opinions that hybridity is a global trend in cultural research, theory and criticism, and one of the most broadly utilized and reprimanded ideas in postcolonial theory, this research is a response to the already extant that western and non-western fusion is practicable. Edward H. Spicer, an anthropologist, depicts that the process of digesting the integration of domestic culture and other culture involves stages of incorporation, assimilation, isolation, and fusion. The acceptance stage here can be considered as a pre-fusion process in which the two separate cultures are coordinated into the perfect third frame. The theories of Spicer (1962) demonstrate that the acceptance and fusion of culture happen in the mutual exchange of two cultures. During cultural hybridization process, traditional components will not die out however will develop into a spectacular form. Tradition isn't something made stale or worn after some time, nonetheless develops throughout the years. From this perspective, this research is an attempt to integrate a non-western element, gamelan with a western element, string ensemble into an ideal hybridized third form. 


\section{Problem Statement}

It is only recently that hybridity has gained visibility in cultural and music studies in East and Southeast Asia region. The notion of cultural hybridity seems particularly attractive to studies of popular music. Several studies have attempted to study the possibilities of hybridity elements in local music genres (Oh, 2013; Ryoo, 2009; Sim, Kim \& Lee, 2017; Shim, 2006), who dedicated their research to study the newly coined cultural phrase, Korean wave. However, in Malaysia, cultural fusions that theorize cultural hybridity as a globalization practice remain rare. To some extent, this rarity mirrors the paucity of cultural and music scholars directly engaging cultural hybridity in Malaysia, although one can find few articles based on cultural hybridity involving Javanese gamelan (Ackermann, 2012; Andrews, 2017; Chacko, 2010; Spiller, 2009; Sutton, 1996 \& 2010; Wappel, 2016; Wozniak, 2014). However, discussion of hybridity involving traditional Malay music elements point to an emerging saliency. This trend underscores the need for a critical theorizing of hybridity in the context of traditional Malay music elements.

The aforementioned phenomena make us questions ourselves: how do we engage ourselves in this kind of revolution? This is an important question that needs to be answered by researchers in music education. Research needs to be extended to include focus on theorizing hybridity in combining or blending both western and non-western tradition. The researcher decided to design a hybrid project that would cross cultural boundaries and bring the researcher into music and interpersonal dialogue between western and non-western elements. To what extend are musical conventions able to adapt when force to collaborate? Are music and traditional practitioners satisfied that their traditions are respected throughout a process of creation and hybridization? Can innovative outcomes from a hybridization project respectfully represent cultural hybridity? These were the formative questions that shaped the researcher's thinking and led the researcher to conceptualize a study in which two distinct elements were brought together to create a work of intercultural beauty, respectful to both musical traditions and to the artists who practice them.

\section{Purpose of the Study}

This study aims to delineate the way in which one particular non-western tradition can be combined with western instruments and traditions to create a work of intercultural beauty, respectful to both musical tradition and to the artists who practice them. Using analytical ideas drawn from hybridity theory, this study sought to produce a new arrangement for string ensemble using selected traditional Malay gamelan repertories. This newly hybridized composition will make every effort at imitating the beautiful and authentic sound of Malay gamelan using are number of advanced string playing techniques such as arco, pizzicato, snap pizzicato, nail pizzicato, col legno and harmonic. Some of the techniques have been utilized in the orchestra's repertories and the used of these techniques allow the audiences to explore the new hybridized form of Malay gamelan repertories.

Following the hybridization process, the next step would be developing instructional material for teaching intermediate university-level string ensemble class. The hybridized repertories will be used as instructional material in the string ensemble class. Students will be presented with the selected pieces for practicing and assessment purpose.

Based on the purpose of the study mentioned above, the objectives of the study are to: 
i. Produce new arrangement for string ensemble using selected traditional Malay gamelan repertories.

ii. Develop an instructional material that incorporates Dick and Carey's (Dick, Carey \& Carey, 2005) instructional system design which is suitable and practical for teaching intermediate university-level string ensemble class using newly hybridized traditional Malay gamelan repertories.

\section{LITERATURE REVIEW}

Literature review examines existing literature based on the foundation of cultural hybridity and learning theories. Figure 1 provides an illustration of a literature map that shows a visual summary of the literature reviewed to provide direction for the study. To begin with, in the first section, this chapter establishes a basic understanding of cultural hybridity theory. Next, brief discussion of gamelan was provided to provide background information. In what follows, the study examined literatures concerning western influence in gamelan music which has mushroomed since the acceptance of cultural hybridity in music environs.

The second section concentrates on reviewing literatures related to instructional material designing process. At the outset, this section establishes the basic understanding of learning theories and their implications for the instructional design process. Considerations were made based on an instructional design process framework from the viewpoint of objectivist and constructivist epistemologies. In addition, this section explores the implications of learning theory on teaching strategies, particularly in the context of teaching university-level string technique classes. Set against the theoretical background of objectivism and constructivism, this section also considers the assessment aspects of a string technique class. Issues revealed in the way the instructional designed is applied, teaching strategies are incorporated, and evaluation is conducted are reviewed.

The purpose of the above literature review was to provide a variety of information about what former and current educators have experienced within this new paradigm of music education. This literature review provides an array of information regarding this subject matter from the theoretical perspective of learning theory, instructional design, components of instructional design, teaching strategies, and assessment and evaluation. This literature review provides an informative and useful framework for music educators to personalize and adopt this new paradigm in their daily teaching routine towards becoming more efficient and effective educators. Figure 2 depicts the conceptual framework for this study which was generated based on this literature review. 
INTERNATIONAL JOURNAL OF ACADEMIC RESEARCH IN BUSINESS AND SOCIAL SCIENCES Vol. 9, No. 2, Feb, 2019, E-ISSN: 2222-6990 @ 2019 HRMARS

Malay Gamelan and String Ensemble Cultural Hybridity: Instructional Material

Development for Teaching Intermediate University-level String Ensemble Class Using

Gamelan Repertories

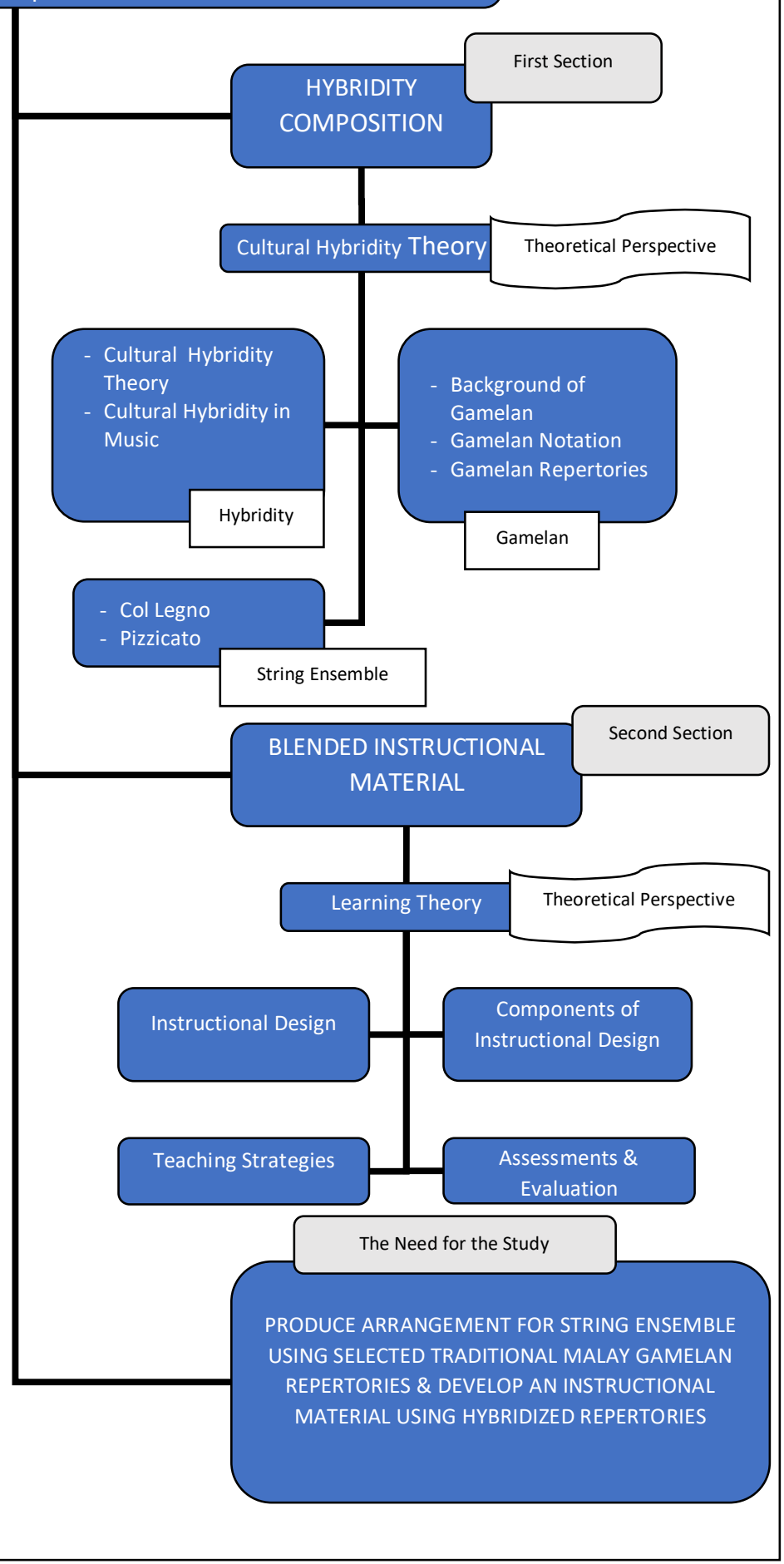

Figure 1: Literature Map 
INTERNATIONAL JOURNAL OF ACADEMIC RESEARCH IN BUSINESS AND SOCIAL SCIENCES Vol. 9, No. 2, Feb, 2019, E-ISSN: 222 2-6990 @ 2019 HRMARS

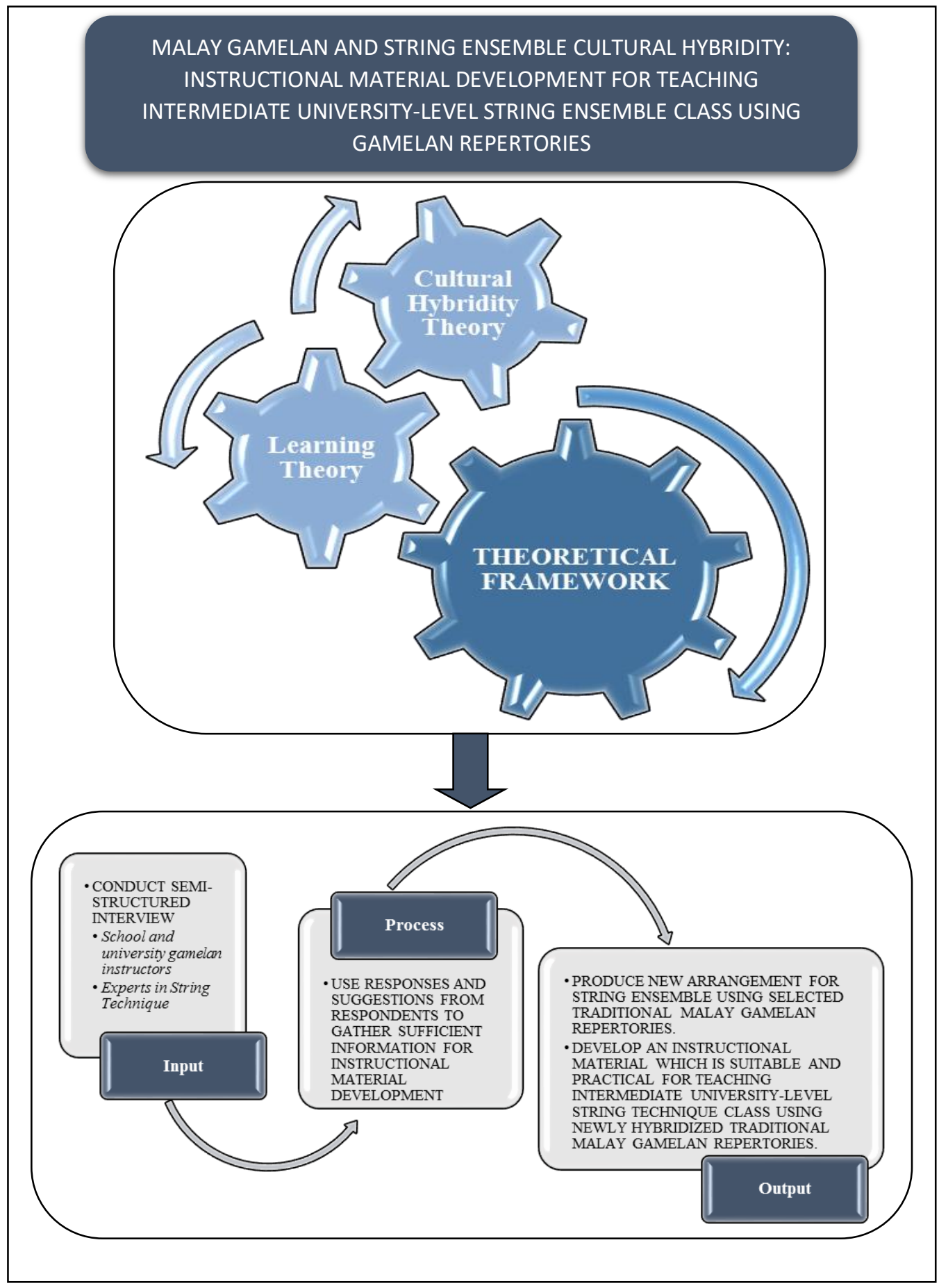

Figure 2: Conceptual Framework

\section{METHODOLOGY}

The study utilized a qualitative approach. The instrument selected for data collection was the semistructured interview format. Respondents for the study which includes music and traditional music 
experts will be interviewed on the type of gamelan repertories suitable for use in this new form of cultural hybridity. Apart from that, respondent will be interviewed to identify the appropriate techniques that can best replicate the authentic gamelan sound. In string performance, there are number of advanced techniques that have been used such as pizzicato, arco, col legno and harmonic. Some of the techniques have been utilized in the orchestra's repertories and the used of these techniques allow the audiences to explore a new sound. During the interview, questions posed to the respondents were on the issues related to cultural hybridity and the suitability of the aforementioned advanced techniques in replicating the authentic gamelan sound.

Results of the interviews will be analyzed as preparation for the instructional material development process. For each questions of the research instrument, responses will be collated and summarized according to the similarity of the answers from the respondents. Based on the responses and suggestions provided by these respondents, the researcher will choose the traditional Malay gamelan repertories to be used in the instructional material. On top of that, the researcher will decide the best advanced technique that can best replicate the authentic gamelan song.

The next step in the research will be the instructional design process development. Instructional material for teaching gamelan and string ensemble in intermediate university-level string technique course will be developed based on the results obtained from responses and suggestions provided by respondents of the study.

In what follows, the researcher will sought advice from two experts to verify the validity of the designed instructional material i.e. one string technique experts and one gamelan expert. The panelist have years of experience in their field. The panelist will be asked to review the designed instructional material and complete the content validity form. The panelist will then be asked to examine the contents of the designed instructional material lesson plans and the prepared musical pieces for performance (which involves blending non-western traditional Malay gamelan music repertories with western string ensemble formal structures and perspectives) in order to determine its appropriateness. The research design is illustrated in the figure 3. 
INTERNATIONAL JOURNAL OF ACADEMIC RESEARCH IN BUSINESS AND SOCIAL SCIENCES

Vol. 9, No. 2, Feb, 2019, E-ISSN: $2222-6990$ ๑ 2019 HRMARS

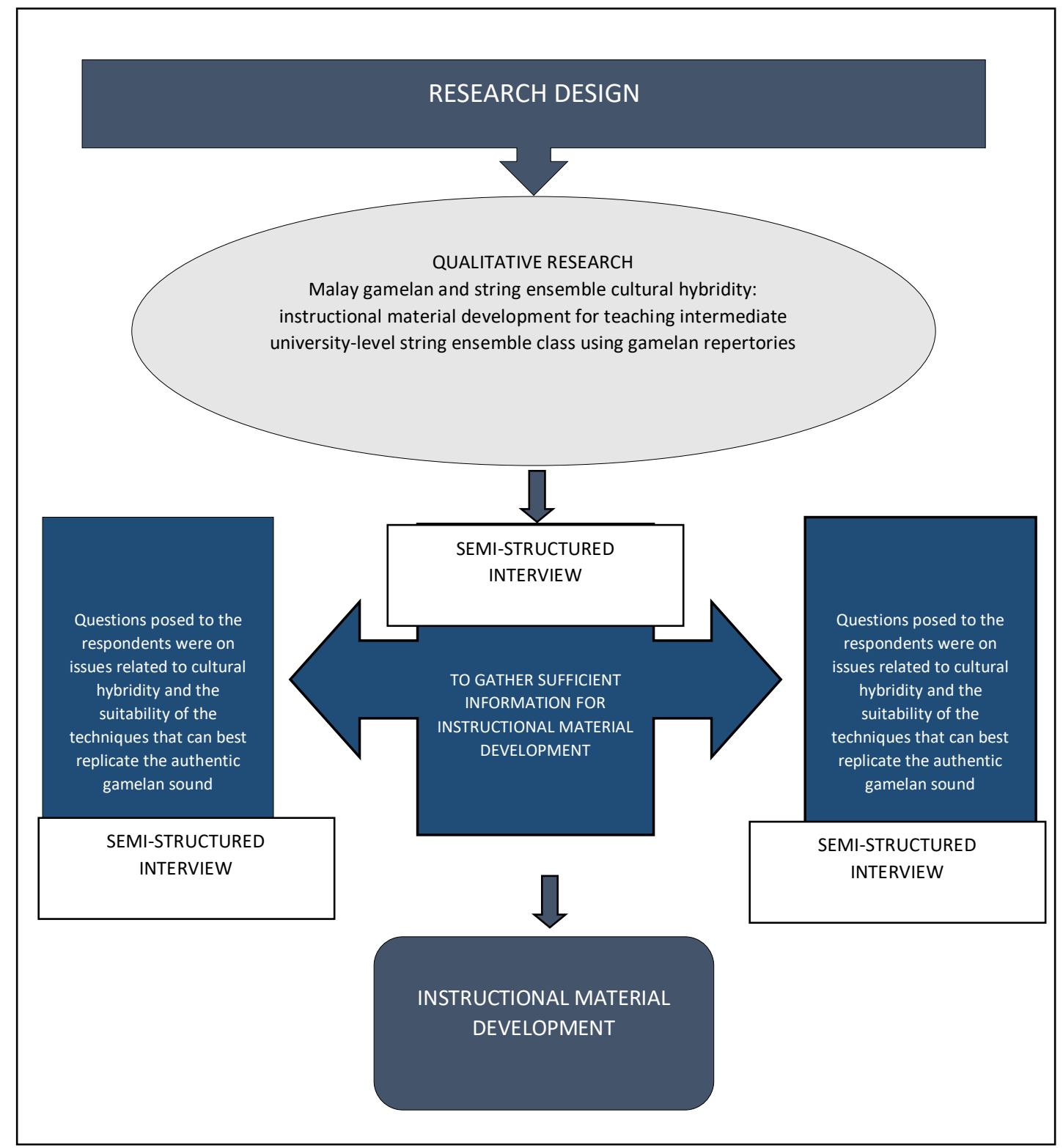

Figure 3: Research Design

\section{RESULTS}

Five respondents took part in the semi structured interview process between February and December 2018 totaling more than 300 minutes. Comments from respondent 4 and respondent 5 were not published seeing that respondents chose to not be identified in reports made available outside the research teams and in publication. Background information of the respondents are summarized in Table 1. Three primary themes were identified throughout the interview. Verbatim comments to support these themes are presented in Table 2. 
INTERNATIONAL JOURNAL OF ACADEMIC RESEARCH IN BUSINESS AND SOCIAL SCIENCES

Vol. 9, No. 2, Feb, 2019, E-ISSN: $2222-6990$ ๑ 2019 HRMARS

Table 1: Background Information of Respondents

\begin{tabular}{|c|c|c|}
\hline Respondent & Expertise & Information \\
\hline $\begin{array}{c}\text { Respondent } \\
1\end{array}$ & String & $\begin{array}{l}\text { - Graduated with master in performance } \\
\text { - Teaches violin, viola and cello } \\
\text { - } 10 \text { years teaching experience } \\
\text { - Have been playing orchestra for more than } 25 \text { years } \\
\text { - } \text { chave playing experience in orchestra, quartet, } \\
\text { chaet and trio performances. }\end{array}$ \\
\hline $\begin{array}{c}\text { Respondent } \\
2\end{array}$ & String & $\begin{array}{l}\text { - } 15 \text { years' experience as violin player } \\
\text { - Currently concentrating on academic side and } \\
\text { writing }\end{array}$ \\
\hline $\begin{array}{c}\text { Respondent } \\
3\end{array}$ & $\begin{array}{l}\text { Ghazal, } \\
\text { Composition }\end{array}$ & $\begin{array}{l}\text { - Actively involved in Ghazal since childhood } \\
\text { - Graduated with degree and doctorate in } \\
\text { Composition }\end{array}$ \\
\hline
\end{tabular}

Table 2: Themes and Representative Verbatim Comments

Theme Comment

1. Awareness of Cultural Hybridity

- Opinion on cultural hybridity phenomena in Malaysia and throughout the globe

"I don't have any comments."

Respondent 1

"Cultural hybrids are actually handful. It does not focused on one thing. But I want to know what hybrid culture means in this context. If I knew in what context, I might am able to give my opinion."

Respondent 2

"In my view, hybrid is a foreign term to the ears of the general public except academician. Academicians are familiar with this term because we always read. But general public are not familiar with this term. Hybrid phenomenon does exists and often practiced by Malaysians themselves. They just do not know what it is. Only academician are aware of this phenomenon." Respondent 3

(Continued) 
INTERNATIONAL JOURNAL OF ACADEMIC RESEARCH IN BUSINESS AND SOCIAL SCIENCES

Vol. 9, No. 2, Feb, 2019, E-ISSN: 2222-6990 C 2019 HRMARS

Table 2 (Continued): Themes and Representative Verbatim Comments

Theme Comment

- Major changes in the cultural hybridity trend in Malaysia

"I don't have any comments."

Respondent 1

"If the changes is something new then it is going to be interesting. But if it's not something new but just rebranding it, I do not think so. But if something new suitable with the instrument playing it, it is acceptable then. But if this new elements still uses the old technique, I don't its appropriate seeing that adapting to changes is difficult when we are attached to the traditional way. But if it is applied to a new genre it's a good thing for the string instrument because we are not only focused on a traditional way we know. We update. You have my support in any effort to improve the instrument itself."

Respondent 2

"Due to the lack of hybrid awareness, the younger generation usually choose inappropriate approach in developing their traditional culture which originally are hybrid in nature. They are overwhelmingly influenced by popular culture. This trends led to compositions that creations that leans towards simplicity. We leave behind the artistic values that subsist in Malay authentic traditional culture. We simplified it. We even agree to include popular elements such pops, the western pop actually, hip-hop, k-pop, k-pop melayu and hip-hop melayu."

Respondent 3

Theme Comment

2. Problems with cultural hybridity (a hybrid of gamelan and string ensemble)

- What respondent feel about hybridizing gamelan and string ensemble

"I like it. I already saw some video records. Ensembles using traditional instruments together with the classical instrument. I like this coloration and how they produce sound."

Respondent 1

"It is possible but limited if we only formulate improvement. Traditionally, gamelan is a simple instrument. There are only seven of them. If we focus on the traditional it will be the same thing. But if we want to formulate improvement in terms of hybridizing strings and gamelan there should be any problem. But we have to establish targets or aspiration."

Respondent 2

(Continued) 
Table 2 (Continued): Themes and Representative Verbatim Comments

\begin{abstract}
"In my view, gamelan Melayu is different from the original gamelan which originate from Javanese Gamelan. When the gamelan was brought into the Malay lands, it underwent hybridity process creating a distinct genre of gamelan called Malay gamelan. Even though the later uses the same instrument, but both gamelan differ in playing technique. The terms used are also different. Thenceforth, we were able to develop our own Malay repertoire for gamelan even though this repertoire does not exist in Java, its native land. Gamelan Melayu itself is hybrid. If you want it to be hybridized with string ensemble, there should not be a problem. I think it is appropriate for hybridization attempt. In terms of sound, both were from different zone. Strings with its sound generated through vibration of the string and gamelan from iron or bronze. So I think the composer will be inspired by this lavish ideas when he processes a much wider spectrum of sound rather than one type of instrument alone. I do not think there is any problem to hybridize both. It is going to be a very interesting attempt."

Respondent 3
\end{abstract}

Theme Comment

- Positive/negative impacts does this hybridizing process has on Malaysian music or culture

"I can say only in positive way. For me everything that going on is just research process. It will give positive outcome. You try and mix everything together. Give some result. Even if you are not satisfied in it, it still positive."

Respondent 1

"Actually, it's up to those who see and hear it because if the individual feels this process is the wrong way to play an instrument, it means that the person cannot accept it. But if we see this hybridization process as something new for us to upgrade, it is a good opportunity to learn and expand our knowledge since we are tightly bound to the old customs. If we still stick to the old ways, it will still be the same. It will not generate something new."

Respondent 2

"If we want to know positive or negative usually after the work is presented. But in a creative process it is a risk that composers have to go through because creativity is a mysterious process. But when it comes to the history of creation or composition, hybridization of gamelan and strings have been done by many composers for example Pak Ngah, composer from ASWARA, Istana Budaya through Bronze Guitar Concert which I personally have participated. 
Table 2 (Continued): Themes and Representative Verbatim Comments

The concerts combines string and gamelan. In my own experience participated as audience in concerts as which hybridized gamelan and strings, I find that it is difficult in terms of tuning seeing that gamelan has fix pitch. So the strings have to tune him with gamelan. In this form of a concert, tuning is the key element. All of these challenges that will produce positive impact later on. When it comes to tone, tone colour is different. If we learn orchestration, different tone colours and combine at the same time will produce a hybrid sound rather we mix instruments with the same material, iron, for example. It will not produce be anything interesting because its tone colour is almost similar. We highly needed the power of composition to differentiate both element. But in hybridizing gamelan and string attempt, the tone colour is different. A wide variety of composition can be done. I believe many positive impact will occur in hybridization process. Just be careful in the approach we use. When we want to blend the strings with gamelan, will it still play classically or follow the gamelan approaches. The instrument does not matter. But that approach is the core element."

Respondent 3

Theme Comment

- Possible challenges that might arise from the hybridization endeavours

"From my opinion the challenge would be in balancing the sound of traditional instrument and string section. For example if its gamelan, it's quite bright and bigger sound. So the string section need to have many players or have another tools to arise the sound and balance it. But I prefer do not using microphone. Because it will change the live sound of the instrument. I prefer live sound of all the instruments. This will be the challenge."

Respondent 1

"What I see is a challenge in terms of acceptance of people who see and hear. Sometimes when he only hears he does not know how it was produced. If he watch and listen, maybe he will notice the new elements. Acceptance of the person who hears and sees is up to the individual. In dealing with these challenges, we have to explain that the traditional way is not totally left out. It is just a new way of playing. That's what we need to explain. Problems will arise if we adapted the new ways and totally abundant the old tradition. Professional musician who have many years of experience in music might object to this phenomena. If we suddenly change to something new. That's a bit difficult. But if the new thing is to improve, it should not be a problem. Because our world is increasingly changing. If you're tied to what's there, we will not be looking further. It's up to the individual who sees it. This individuals is not necessarily a less knowledgeable individual. Sometimes high-educated individuals do not agree because he cannot accept when a customarily instrument played by hitting the instrument we swap the technique to hitting it to other instruments

(Continued) 
INTERNATIONAL JOURNAL OF ACADEMIC RESEARCH IN BUSINESS AND SOCIAL SCIENCES Vol. 9, No. 2, Feb, 2019, E-ISSN: 2222-6990 C 2019 HRMARS

Table 2 (Continued): Themes and Representative Verbatim Comments

Here are some of the challenges that we need to face. For now the best solution is to explain and give an understanding."

Respondent 2

\section{Theme Comment}

- $\quad$ Is it appropriate if in the hybridization process involves only the string itself?

"There is no problem because in Malay culture we can formulate, tools are not the main thing in the processing of creativity. Almost all the Malay tools themselves are imported from the outside world. For example if we said gambus is a Malay tool it is not appropriate. Harmonium is Malay, also not appropriate. Tools are not the main element in Malay culture. So if you want to use this approach, there is no problem because we only infuse Malay gamelan elements into string ensemble. It is still considered a hybrid where the spirit of Malay culture is transferred. It was not abandoned."

Respondent 3

- Should the string be merged with gamelan or just a string?

"In my view it can join or stand alone. Both method is possible."

Respondent 2

3. Suggestions on suitable gamelan repertories

- Does string instruments have the capability of imitating authentic gamelan sound?

"Not exactly but it will be not so bright of course like gamelan because but some bowing patterns can somehow imitate gamelan sound."

Respondent 1

"It will not imitate entirely but possible through new playing technique. The idea is that the plucking technique is just not solely plucking but with additional support for example hold near the bridge and pluck. It is impossible if we use the traditional techniques but it is achievable will the help of extra support technique."

Respondent 2

"As far as I know, string has the ability to imitate the sound of nature for example the sound of birds, humans and sound of the door closing. I believe the strings have the ability to go beyond that. Perhaps the composer will be more creative here. Perhaps Col Legno is one of the techniques that can be used to imitate the sound of idiophone knocking or iron part knocking on the open string or when it is pressed. It becomes an interesting exploration and experimentation later on. I believe strings instrument have the potential to do that."

Respondent 3

(Continued) 
INTERNATIONAL JOURNAL OF ACADEMIC RESEARCH IN BUSINESS AND SOCIAL SCIENCES

Vol. 9, No. 2, Feb, 2019, E-ISSN: 2222-6990 C 2019 HRMARS

Table 2 (Continued): Themes and Representative Verbatim Comments

Theme Comment

- Recommended gamelan repertories suitable for string ensemble, where the string can imitate the sound of gamelan

"I really not familiar with gamelan repertoire and do not remember any gamelan song title. But I think it could be done on all the string section. The violin, viola and cello and also double bass. I cannot comments more in details."

Respondent 1

"I think any song can imitate gamelan because string is full scale instrument. Violin can imitate gamelan but gamelan hardly can imitate violin seeing that violin is a full scale instrument. Except gamelan seven. But if it is for string, violin, viola, cello or double bass have the capability of imitating gamelan sounds."

Respondent 2

"I do not memorized all the repertoires. According to my experience, the classical repertoire of Gamelan can be used for example of Togok, Ayak-Ayak, Timang Burung and Perang. But maybe if there are too many traditional songs, it can make used of newly composed song by Malaysian composer for gamelan. We can perceive whether string ensemble have the ability to play a traditional gamelan song as well as the newly composed Malay repertoire. Maybe from Pak Ngah's works. Also works from a composer from ASWARA."

Respondent 3

- Recommended string technique that have the capability of imitating gamelan sound "I think it's only bow pattern called col legno when you use the bow hitting the string."

"Maybe pizzicato. You need to try and see how it turns out."

Respondent 1

"We still need extra techniques for col legno. We may have something on the wood as support or on the bridge. Perhaps the traditional people do not agree with this. The bridge must be touched. If not the projected sound will still be the same. Sound of string instrument circulate on bridge. The bridge will lower the sound into the body, circulate it and projected the sound. The bridge is actually the forte for violin. That's what I can say based on the experience of studying violin structure."

Respondent 2

(Continued) 
INTERNATIONAL JOURNAL OF ACADEMIC RESEARCH IN BUSINESS AND SOCIAL SCIENCES Vol. 9, No. 2, Feb, 2019, E-ISSN: $2222-6990$ ๑ 2019 HRMARS

Table 2 (Continued): Themes and Representative Verbatim Comments

Theme Comment
"In my view, in some situations the western notation system is very helpful in
conveying the nusantara expression. Especially related to rhythm. If we want to read
the rhythm using nusantara system of notation, it will be very difficult because
numbering does not represent rhythm. Usually numbering represents pitch. If we
want to make more sophisticated compositions using dots and lines it's too hard for
us to write. As a result, it will slow down the process. In my view, the western notation
composition can be used as long as we place an indication for each not and the
frequency. I do not see this process as a process of westernization but more to
facilitate it. So far, traditional or ghazal Malay music artists have been using and are
already comfortable with the use of western notation. But as long as the notation is
written with the exact melody and harmony, there should not be a problem. The
notation is solely the medium to convey the music alone but not the music itself."
Respondent 3

\section{DISCUSSION}

The researcher conducted this qualitative study with respondents both from gamelan and string experts to better understand issues related to cultural hybridity and the suitability of the techniques that can best replicate the authentic gamelan sound. By considering the perspectives within and across each interview, we identified several themes that may help comprehend cultural hybridity process and produce new arrangement for string ensemble using selected traditional Malay gamelan repertories. From there onwards, the researcher will then develop an instructional material which is suitable and practical for teaching intermediate university-level string technique class using newly hybridized traditional Malay gamelan repertories.

Our study identified that most common people are not familiar with the term hybrid culture. Responding to question posed regarding hybrid awareness, Respondent 3 emphasized that:

In my view, hybrid is a foreign term to the ears of the general public except academician. Academicians are familiar with this term because we always read. But general public are not familiar with this term. Hybrid phenomenon does exists and often practiced by Malaysians themselves. They just do not know what it is. Only academician are aware of this phenomenon. Hybrid is indeed a key identity of the Malaysians. The authenticity of Malay tradition hinge on the hybrid nature itself. We cannot compare our tradition with the arts in Indonesia where cultural fusion is scarce. For example, compare Malay to Javanese. Javanese uses a slendro pelog scale. Contradictory, Malays use a more tonal scales, diatonic. But our repertoire is still known as the Malay repertoire. So Malay tradition authenticity rest on the hybrid traits. Hybrid has become a Malay tradition. I reckon theorists finds the hybrid word after the Malays have practiced them for many years. Common people are not knowledgeable of hybrid in terms of theoretical paradigm. They just practice hybridity. Perhaps they are more 
used to the term mixed-culture or cross-cultural. They relate more to terms that are easier to digest.

Thus, the hybrid phenomenon has long been established in our society but it is not commonly known as cultural hybridity. For example, the gamelan itself does not originate from Malay land but instead is brought in from neighbouring countries. A famous composer, Manan Ngah accentuated that hybridity have long been practiced in Malaysia as part of globalization process. He emphasized:

There must be an awareness in music that we have what we have. We should be prepared to take from outside what we feel is more appropriate-we don't have to feel superior or inferior. This is a fact which has always been with us from before. And when we look at our own history, it is evident that our forefathers then were more progressive and innovative than we are now with the existence of Joget, Dondang Sayang, Nasyid, and Ghazal, and others... In reality, our ancestors had much earlier on created a synthesis or a hybrid form as a product of integrating the aesthetic values of Hispanic, European, Arabic, Indian, and Chinese origins into Malay artistic work (cited in Ibrahim, 1995, p.5)

Honourably, Malaysian culture and music has dependably been luminous, liquid and pliable to outside impacts. This is factual to some degree since hybridization is an imperative norm for Malay character.

Secondly, regarding positive or negative impact of hybridizing process, all respondents concur that this hybridization attempt should yield positive impact. Hence hybridization is possible seeing that attempts have been made before to hybridize music as put forward by Ibrahim (2016):

In light of this new musical consciousness and the move to assert a new musical genre, it came to no surprise that TV3 Musik-Musik also took on a pro-active role by delineating a separate category called Irama Malaysia (Malaysian Rhythms). This was seen as a way to recognize the Balada Nusantara musical genre created by Manan Ngah and M. Nasir. Using the new format, Musik-Musik also began to give annual recognition and awards to the winning Nusantara compositions. In this way, the TV show indirectly encouraged music producers and songwriters to compose songs which creatively blended new and traditional musical elements (p.35).

Respondent 3 also acknowledge the same agreement stating "... when it comes to the history of creation or composition, hybridization of gamelan and strings have been done by many composers for example Pak Ngah, composer from ASWARA, Istana Budaya through Bronze Guitar Concert which I personally have participated".

Moving on the capability of imitating the sound of gamelan, respondents have the same opinion that string instruments have the potential in imitating gamelan sound. They suggested pizzicato and bowing technique of col legno to be used to imitate idiophone sound of gamelan. Additional technique might be needed to produce similar sound made by gamelan as proposed by respondent 2:

It will not imitate entirely but possible through new playing technique. The idea is that the plucking technique is just not solely plucking but with additional support for example hold 
INTERNATIONAL JOURNAL OF ACADEMIC RESEARCH IN BUSINESS AND SOCIAL SCIENCES

Vol. 9, No. 2, Feb, 2019, E-ISSN: 2222-6990 C 2019 HRMARS

near the bridge and pluck. It is impossible if we use the traditional techniques but it is achievable will the help of extra support technique.

At first there are a sum of 77 unique Gamelan Terengganu melodic titles which was named after the names of the dance they accompanied. All things considered, just 62 repertories were prominent today and just 13 pieces are ordinarily performed. Of all this pieces respondents suggested Togok, Ayak-Ayak, Timang Burung and Perang to be used in the hybridization process.

\section{CONCLUSION AND IMPLICATIONS}

By exploring gamelan and string expert's perspectives on gamelan and string ensemble hybridization, we identified that this hybridization process is possible and practical. These respondents concur that string instruments have the capability of imitating authentic gamelan sound.

Using analytical ideas drawn from hybridity theory, this study sought to produce a new arrangement for string ensemble using selected traditional Malay gamelan repertories. Following the hybridization process, instructional material for teaching intermediate university-level string ensemble class were developed. The hybridized repertories will be used as instructional material in the string ensemble class. Students will be presented with the selected pieces for practicing and assessment purpose. It is suggested that in future research, it would be beneficial for the researcher to explore the impact of the newly design instructional material on student achievement and satisfaction in Malaysian university-level intermediate string technique classes.

This study is beneficial to the researcher as a music educator, as well as other music educator throughout the country. This study may help fill gaps and opening in literature concerning cultural hybridity in the context of Malaysian music and cultural atmosphere. It will also assist in establishing a wider spectrum of research based on Malay gamelan and cultural hybridity. The results of this study may help delineate the way in which one particular non-western tradition can be combined with western instruments and traditions to create a work of intercultural beauty, respectful to both musical tradition and to the artists who practice them. Specifically, the results of the study will assist music educator in developing instructional material which hybridized other Malaysian traditional music with western instruments. This research will provide constructive information for music educators in the development process to construct an effective and practical instructional material.

In the context of formal music education in Malaysian universities, cultural hybridity studies seems to be a helpful platform to promote local music traditions to the students in a new and prolific way. Research conducted by Shah \& Masumi (2016) ascertain that gamelan, “...being a traditional form of music/ensemble, there may be some students who are not really interested in playing the gamelan, as they feel it is rather easy to play" (p.71). So, how do we attract these students to play traditional music instruments? This new form of hybridity is hoped to be appealing to these students and attract their interest to learn gamelan. The designed instructional material will help exposed the students to the beautiful and authentic sound of gamelan but in the form of string ensemble. It is hoped that this preliminary exposure will help in increasing students' interest in learning to play gamelan itself. On the other hand, cultural hybridity helps promotes Malay gamelan to the world. 
This study may help fill gaps and opening in literature concerning cultural hybridity in the context of Malaysian music and cultural atmosphere. It will also assist in establishing a wider spectrum of research based on Malay gamelan and cultural hybridity. The results of the study will assist music educator in developing instructional material which hybridized other Malaysian traditional music with western instruments. This research will provide constructive information for music educators in the development process to construct an effective and practical instructional material.

In the context of formal music education in Malaysian universities, cultural hybridity studies seems to be a helpful platform to promote local music traditions to the students in a new and prolific way. This new form of hybridity would be appealing to these students and attract their interest to learn gamelan. The designed instructional material will help exposed the students to the beautiful and authentic sound of gamelan but in the form of string ensemble. It is hoped that this preliminary exposure will help in increasing students' interest in learning to play gamelan itself. On the other hand, cultural hybridity helps promotes Malay gamelan to the world.

\section{Acknowledgements}

This research was supported by Sultan Idris Education University, Perak, Malaysia under the GPU grant, 2017-0236-107. We thank our colleagues from Faculty of Music and Performing Arts, Sultan Idris Education University who provided insight and expertise that greatly assisted the research, although they may not agree with all of the interpretations or conclusions of this paper.

\section{Corresponding Author}

Shafizan Sabri

Department of Music and Music Education, Faculty of Music and Performing Arts, Sultan Idris Education University (UPSI), 35900, Tanjong Malim, Perak, Malaysia

E-mail: shafizan@fmsp.upsi.edu.my

\section{References}

Ackermann, A. (2012). Cultural hybridity: Between metaphor and empiricism. In Conceptualizing Cultural Hybridization. Berlin: Springer. 5-25.

Andrews, M. N. (2017). Compositional practice as expression of cultural hybridity in Lou Harrison's double concerto for violin, cello and Javanese gamelan. Student Research Symposium.12. Retrieved August 15, 2017 from Portland State University, Website: http://www.pdxscholar.library.pdx.edu/studentsymposium/2017/Presentations/12.

Bramantyo, T. (2009). Intercultural musicology in music education: In search for philosophy of music education in Malaysia. In Colloquium for Music Research.

Burke, P. (2009). Cultural Hybridity. Cambridge: Polity Press.

Chacko, R. E. (2010). Beyond the myth of East-West hybridity: An analysis of Lou Harrison's works for gamelan and Western instruments. Unpublished doctorate thesis, University of Colorado at Boulder. 
INTERNATIONAL JOURNAL OF ACADEMIC RESEARCH IN BUSINESS AND SOCIAL SCIENCES

Vol. 9, No. 2, Feb, 2019, E-ISSN: 2222-6990 C 2019 HRMARS

Dick, W., Carey, L. \& Carey, J.O. (2005). The systematic design of instruction (6th Ed.). Boston: Allyn and Bacon.

Ibrahim, Z. (2016). Disciplining Rock and Identity Contestations: Hybridization, Islam and New Musical Genres in Contemporary Malaysian Popular Music. Situations, 9, 21-47.

Ibrahim, Z. (1995). Popular Culture at the Crossroads: Malay Contemporary Music. Kuala Lumpur: Universiti Malaya.

Oh, I. (2013). The Globalization of K-pop: Korea's Place in the Global Music Industry. Korea Observer, 44(3), 389.

Ryoo, W. (2009). Globalization, or the logic of cultural hybridization: The case of the Korean wave. Asian Journal of Communication, 19(2), 137-151.

Sim, H. C., Kim, S. A., \& Lee, B. M. (2017). K-Pop Strategy Seen from the Viewpoint of Cultural Hybridity and the Tradition of the Gwangdae. Kritika Kultura, (29), 292-317.

Shah. S., M. \& Masumi, M., A. (2016). Teaching traditional music in Malaysian schools: Considering the cultural context. International Journal of Learning and Teaching. 8(1), 69-76.

Shim, D. (2006). Hybridity and the rise of Korean popular culture in Asia. Media, culture \& society, 28(1), 25-44.

Spicer, E. H. (1962). Cycles of conquest: the impact of Spain, Mexico, and the United States on the Indians of the Southwest, 1533-1960. University of Arizona Press.

Spiller, H. (2009). Lou Harrison's Music for Western Instruments and Gamelan: Even More Western than It Sounds. Asian Music, 40(1), 31-52.

Sutton, R. A. (2010). Gamelan encounters with Western music in Indonesia: Hybridity/hybridism. Journal of Popular Music Studies, 22(2), 180-197.

Sutton, R. (1996). Gamelan: Cultural Interaction and Musical Development in Central Java. Crossroads: An Interdisciplinary Journal of Southeast Asian Studies, 10(1), 192-194

Wappel, J. (2016). Gamelan and the modern pedal harp of the west: A performer's perspective on hybridized musical influences in the harp chamber works of Bill Alves, Lou Harrison, and Alan Hovhaness. Unpublished doctorate thesis, Ball State University.

Wozniak, A. (2014). Orientalism, Regionalism, Cosmopolitanism: Musical Manifestations of Cultural Hybridity. Unpublished undergraduate thesis, Wellesley College 